\title{
Endophytic microorganisms of apple fruit (Malus domestica)
}

\author{
A.A. Vankova ${ }^{1, *}$, N.V. Drenova ${ }^{2}, L . A$. Sviridova $^{1}$, and G.A. Golovkin ${ }^{1}$ \\ ${ }^{1}$ Russian State Agrarian University - Moscow Timiryazev Agricultural Academy, 49 \\ Timiryazevskaya str., Moscow, 127550, Russia \\ ${ }^{2}$ All-Russian Plant Quarantine Center, 32 Pogranichnaya, Bykovo village, the city of Ramenskoye, \\ Moscow region, 140150, Russia
}

\begin{abstract}
The plant-associated microorganisms are of key importance in ensuring the quality and safety of plant products. This paper focuses on the study and composition of endophytic microorganisms inautumn apple varieties from domestic selection intended for long-term storage: Bessemyanka Barantseva, Orlovsky Pioner, Alesya and Verbnoe.It was discovered that the internal tissues of fruits are richly populated with microorganisms, the number of which depends on the plant variety and the stage of fruit development. The dominant group is yeast (up to $10^{7} \mathrm{CFU} / \mathrm{g}$ ). The most common speciesis Hanseniaspora uvarum (26,0\%). The number of bacteria averages $10^{2}-10^{4} \mathrm{CFU} / \mathrm{g}$, the dominant species-Lactobacillus sp. $(52,0 \%)$ and Pantoea agglomerans (34,2\%). The soft tissue of the fruits of all studied apple varieties contains mycelial fungi, the number of which, as a rule, does not exceed $10^{2} \mathrm{CFU} / \mathrm{g}$. The dominant species is Cladosporium aggregatocicatricatum (33,3\%). The microorganisms producers of biologically active compounds, promising for agrobiotechnologies, have been identified.
\end{abstract}

\section{Introduction}

Fruits are part of the routine food of a human. They are valuable food products containing a complex of vitamins, trace elements, fiber, sugars, organic acids, vegetable protein and other nutrients that are essential for the organism. Apples account for a significant part of the total amount of fruit consumed by humans. Receiving fresh fruits and vegetables in most of the territory of Russia is limited to a short growing season, therefore, the problem of storing fruit and vegetable products is of great relevance. The economic damage caused by food spoilage is very high.Some studies have shown that a quater of world's food products are being lost. It is connected with the activity of microorganisms. The loss of fruit and vegetable may be up to $50 \%$ [1]. The autumn apple trees may be stored for a long time.During storage, the life cycle of fruits continues: their ripening occurs, as a result of which they acquire a characteristic color, appearance, and taste. The seeds inside the fruit continue to develop. Once they are fully ripe, the fruit begins to wither, loses weight and is subject to diseases. Therefore, the storage time depends on the ripening time[2].

\footnotetext{
* Corresponding author: anna.vankova@gmail.com
} 
The plant is a powerful environmental factor determining the formation and control of its microbiome. The surface of plant organs is populated by epiphytic microorganisms which exist due to exosmosis products. Many epiphytes generate biologically active substances and substantially affect the processes of plant growth and development, as well as prevent the penetration of phytopathogenic bacteria and fungi due to the formation of antibiotics [3].

The internal tissues of plants are populated by endophytic microorganisms. The sources of endophytic microbiota are epiphytes and the environment[4].Endophytic microorganisms are found in stems, leaves, roots, fruits, seeds, flowers, and pollen $[5,6,7,8,9]$ of many cultivated (sugar beet, corn, sorghum, soy, wheat, rice, apple, pear) and wild (oak, poplar, spruce, dandelion, sphagnum mosses) [10]. The endophytic microorganisms are presented by bacteria and fungi from different systematic groups [9,11]. Most endophytic bacteria penetrate into plants through the root system and spread with the flow of water and nutrients [13], as well as through stomata and lenticels [12]. The bacterial endophytes commonly inhabit the intercellular space of plant tissues. Some of them are able to move through the xylem, which is a typical way of pathogens spreading [13]. In the tissues of juicy fruits, the endophytic yeasts are represented, as a rule, by the same species as on the surface, and exist both in the intercellular space and inside large plant cells [9].

The endophytic microorganisms can have a diverse positive effect on plants. The properties of endophytic microorganisms such as providing plants with nutrients are known, especially the supply of nitrogen and phosphorus, the ability to synthesize vitamins and phytohormones that stimulate their growth and stability to stresses of various origin [12].Thus, for example, endophytic yeast Rhodotorula mucilaginosa generates auxin. It is also able to stimulate plant growth [9]. The endophytic strains of g. Pseudomonas form antibiotics like ecomycin and pseudomycin. Produced by endophytes of g. Bacillus surfactant substances, and iturines, phengicins, circulins, colistin and polymyxins defend the host plant from a number of pathogens, possessing antiviral, antibacterial and antifungal properties. [11, 14, 15]. The epiphytic and endophytic bacteria Bacillus amyloliquefaciens, $B$. badius, $B$. gibsonii isolated from apple shoots have a pronounced antagonistic activity in connection with phytopathogenic fungi such as Alternaria alternata, Aspergillus tubingensis, Fusarium incarnatum, Fusarium tricinctum and Phoma fungicola, isolated from the same shoots [16]. It is well known that many mycelial fungi are able to endotrophic existence $[11,17,18]$. Secondary metabolites with diverse biological effects are isolated from endophyte fungi more frequently than from bacteria and actinomycetes. For example, an endophytic fungi Cryptosporidiosis quercina synthesizes the substance cryptoxanthin, active against a number of phytopathogenic fungi, including Sclerotinia sclerotiorum and Botrytis cinerea.

The microorganisms living inside the fruit of the apple tree, as well as the processes they cause, are practically not studied. Yet, it is the microbiome associated with fruits that is of key importance in ensuring their health and safety. The endophytic microorganisms colonize the same ecological niches of the plant as phytopathogens, and thus are very promising as biocontrol agents[15]. The study of endophyte biodiversity will allow to find producers of biologically active substances that can be used in agrobiotechnologies.

This study was launched by the All-Russian Research Institute of the Refrigeration Industry, which designs new technologies for the storage and transportation of plant products[19,20]. 


\section{Materials and methods}

The aim of this assay is to study the number and diversity of microorganisms in the pulp of apple fruits by the phases of vegetation (flowers, ovary, middle of the growing season, marketable maturity), to isolate and identify endophytic microorganisms.

The objects of the study were autumn apple varieties intended for long-term storage: Bessemyanka Barantseva, Orlovsky Pioner, Alesya and Verbnoe. The sampling for the study was conducted on the territory of the Michurinsky Garden of the Russian State Agrarian University - Moscow Timiryazev Agricultural Academy (Moscow, Russia) according to the stages of fruit development: flowers, ovaries, middle of the growing season, and market maturity. The samples were collected in sterile bags from 3 trees of each variety in 5 repetitions. To isolate and account for endophytic microorganisms, the surface of the samples washed with sterile water was sterilized with $96 \%$ alcohol. Control of the sterility of the surface was done by the replica method on MPA (meat-and-peptone agar).The peel tissue was removed from the fruit with a sterile scalpel, sections of internal storage tissues were cut out and crushed, and plating was performed by the standard method on a glucose-peptone medium (GPM). In order to isolate fungi, the medium was acidified with $40 \%$ lactic acid $(4 \mathrm{ml} / \mathrm{l})$ to selectively inhibit bacterial growth. Bacterial cultures were incubated in a thermostat at a temperature of $28^{\circ} \mathrm{C}$, fungi $-24^{\circ} \mathrm{C}$. The grown colonies were separated into morphotypes. Pure cultures were isolated. The incidence was calculated as the ratio of the number of samples in which microorganisms of this taxonomic group were found to the total number of samples, expressed as a percentage. The relative abundance is defined as the percentage of microorganisms of this taxonomic group to the total number of microorganisms found in the sample [21].

To isolate bacterial DNA, $1 \mathrm{~mm}^{3}$ of isolates were resuspended in $200 \mu \mathrm{l}$ of sterile distilled water. The micro-samples with suspensions were heated for $10 \mathrm{~min}$ at $98^{\circ} \mathrm{C}$, cooled on ice, and centrifuged for $3 \mathrm{~min}$ at $7000 \mathrm{rpm}$. The cultures were determined by sequencing a region of the 16S rRNA gene with universal primers 27F/1492R [22]. The amplification was done using Encyclo PCR kit (Evrogen ZAO, Russia). The reaction mixture with a total volume of $25 \mu \mathrm{l}$ included $0.5 \mu \mathrm{l}$ of primers (conc. $10 \mathrm{pM} / \mu \mathrm{l}$ ) and $1 \mu \mathrm{l}$ of DNA; amplification protocol: $5 \mathrm{~min}$ at $96^{\circ} \mathrm{C} ; 35$ cycles: $15 \mathrm{~s}$ at $96{ }^{\circ} \mathrm{C}, 30 \mathrm{~s}$ at $58{ }^{\circ} \mathrm{C}, 60 \mathrm{~s}$ at $72{ }^{\circ} \mathrm{C}$; 5 min at $72{ }^{\circ} \mathrm{C}$.

The DNA of fungi was separated using a kit "Phytosorb" ("Syntol" OOO, Russian Federation). Identification was performed by sequencing a section of the internal transcribed region of the rDNA spacer with universal primers ITS4/5[23]. The

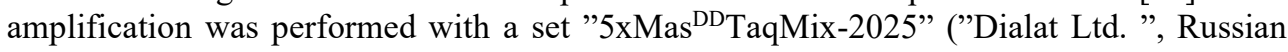
Federation). The reaction mixture with a total volume of $25 \mu \mathrm{l}$ included $1 \mu \mathrm{l}$ of primers (conc. $10 \mathrm{pM} / \mu \mathrm{l}$ ) and $2 \mu \mathrm{l}$ of DNA.

PCR products were visualized by electrophoresis in 1.5 agarose gel. Sequencing was done according to the standard procedure. The "Verity" amplifier and the "3500" genetic analyzer ("AppliedBiosystems", USA) were used in the study. The sequences were edited in "BioEdit"software and identified by comparison with the NCBI database[24].

\section{Results and discussion}

The results of our assay revealed that the internal storage tissues of apple fruits of the studied varieties are populated by microorganisms. They are represented by yeast, bacteria and micromycetes. The number of endophytic microorganisms depends on the apple variety and the fruit development stage (Fig. $1-4)$. 


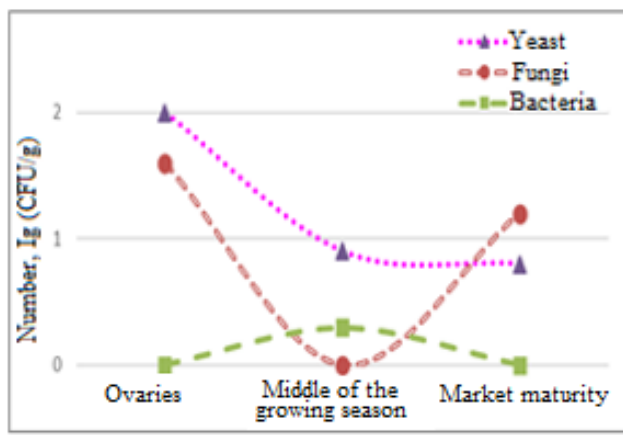

Fig. 1. Dynamics of the number of endophytes in the fruits of the Bessemyanka Barantseva apple variety.

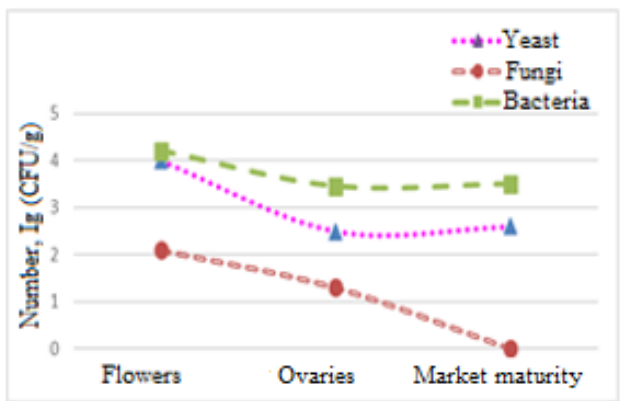

Fig. 3. Dynamics of the number of endophytes in the flowers and fruits of the Verbnoe apple variety.

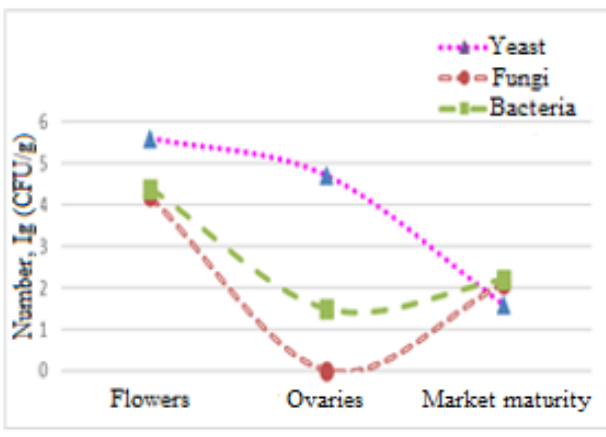

Fig. 2. Dynamics of the number of endophytes in the flowers and fruits of the Orlovsky Pioner apple variety.

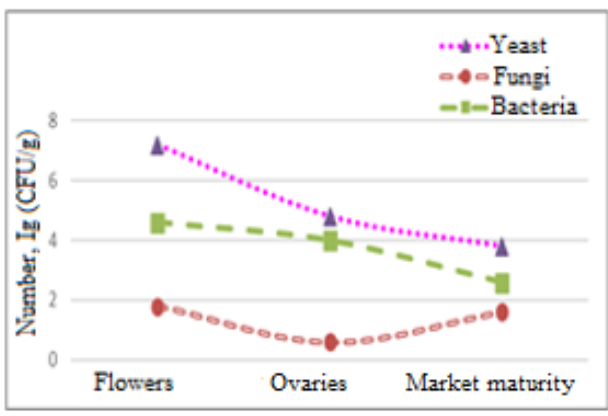

Fig. 4. Dynamics of the number of endophytes in the flowers and fruits of the Alesya apple variety.

Yeast is the dominant group of endophytes, with the exception of the Verbnoe variety. The maximum number of yeasts was detected in the flowers of the Alesya apple variety $10^{7} \mathrm{CFU} / \mathrm{g}$ (Fig. 4), the minimum is in the fruits of market maturity of the Bessemyanka Barantseva variety (Fig. 1). The maximum number of bacteria $-10^{4}-10^{5} \mathrm{CFU} / \mathrm{g}$ was also revealed in the flowers of the Alesya variety (Fig. 4), the minimum was in the fruits of the Bessemyanka Barantseva in the middle of the growing season; no bacteria were identified in the ovaries and ripe fruits of this variety (Fig. 1). The mycelial fungi were detected in the fruits of all the studied apple varieties, the number of which does not exceed $10^{2} \mathrm{CFU} / \mathrm{g}$. The exception is the Orlovsky Pioner variety. In the dynamics of the number of endophytes, there is a general tendency to decline in the number of microorganisms as the fruits ripen.

The identification findings have provided an opportunity to establish the species identity of the isolated microorganisms, to evaluate their occurrence and relative abundance in the internal tissues of apple fruits (Fig.5). 


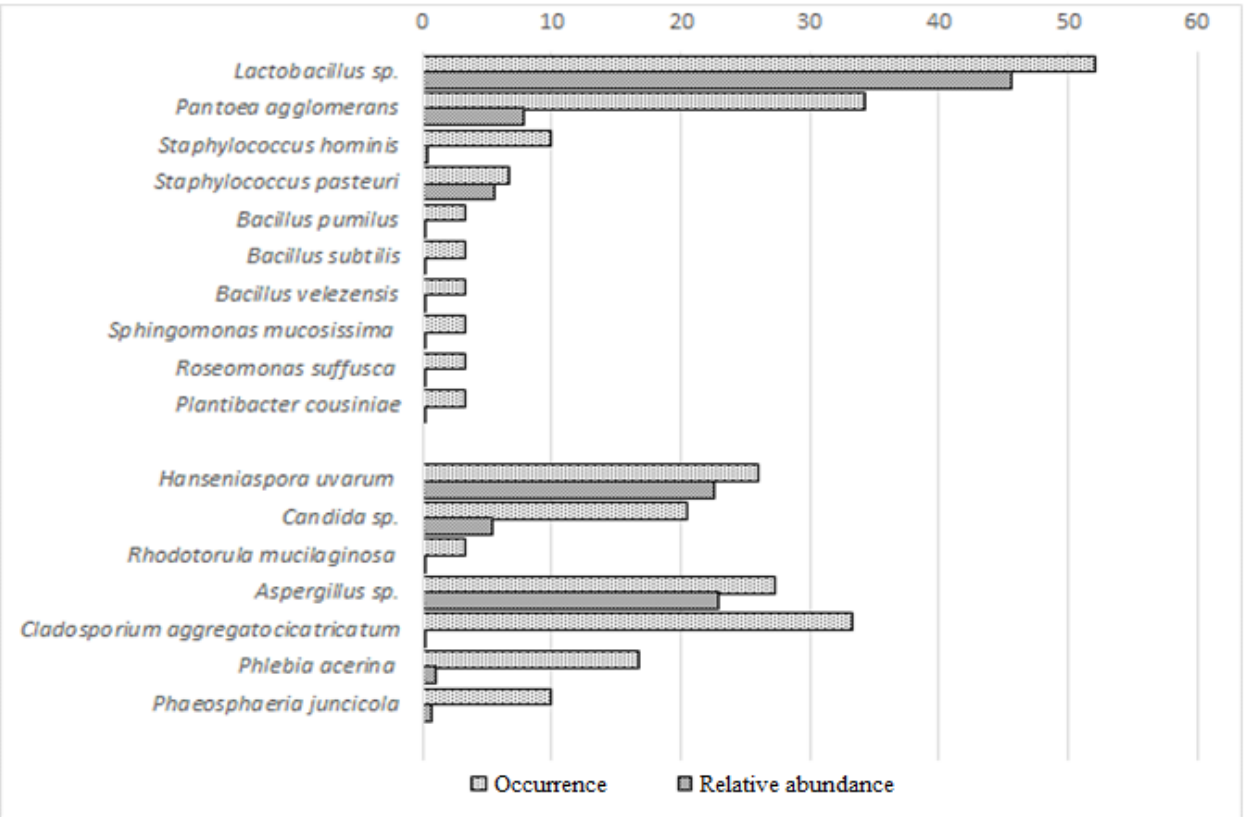

Fig. 5.The occurrence and relative abundance of microbial species inside apple fruits (average by vegetation phases), $\%$.

Totaly, 10 species of bacteria, 3 species of yeast and 4 species of micromycetes were isolated. The following bacteria Lactobacillus sp. (52,0\%) and Pantoea agglomerans $(34,2 \%)$ were mostly common; as for yeasts: Hanseniaspora uvarum $(26,0 \%)$ and Candida sp. (20,5\%), mycelial fungi: Aspergillus sp. (27,3\%) and Cladosporium aggregatocicatricatum $(33,3 \%)$. The relative abundance of the same species of microorganisms was mostly the greatest. The most representative genera were Bacillus. 3 species of them were isolated. Also, two species of g. Staphylococcus were isolated. The remaining genera are represented by single species.

The findings of the study revealed that the internal storage tissues of fruits and apple flowers are a favorable habitat for many microorganisms, as evidenced by their high abundance and diversity. The maximum number of bacteria and yeast $10^{4}-10^{7}$ $\mathrm{CFU} / \mathrm{g}$ wasfound in the flowers of the apple tree, from which the ovaries are formed, and then the fruits. The floral nectar is a rich nutrient medium for microorganisms due to its high content of carbohydrates, amino acids, vitamins and other valuable substances. The flowers are easily infected by insect-pollinators. Thus, the number of yeasts in floral nectar can reach $10^{8} \mathrm{CFU} / \mathrm{g}$ [9]. Hanseniaspora uvarum was the predominant species of yeast in the flowers and fruits of the studied varieties, Lactobacillus sp absolutely dominated among the bacteria. These species of microorganisms are recognized as common epiphytes and endophytes of fruits and vegetables [1,3,9]. During the formation of fruits at the ovary stage, a decrease in the number of microorganisms is noted, which is obviously due to a decline in the amount of carbohydrates and a rise in acidity. By the stage of market maturity, an increase in the number of Aspergillus sp. fungi was found in the fruits of the varieties Bessemyanka Barantseva and Orlovsky Pioner. It should be mentioned that fungi act as the main agents of spoilage of apples during storage[1].

An analysis of the functional features of microorganisms isolated from apple fruits identified species with growth-stimulating, fungicidal and bactericidal activity: Bacillus 
subtilis, Bacillus velezensis, Sphingomonas mucosissima, Pantoea agglomerans, Lactobacillus sp., Rhodotorula mucilaginosa, Staphylococcus pasteuri. Meanwhile, a phytopathogenic bacterium Bacillus pumilus has been found. It is known as the causative agent of spoilage of food raw materials and food products. Cladosporium aggregatocicatricatum is a common storage mold which can evolve at subzero temperatures, causing rot of fruits and vegetables [1].

\section{Conclusions}

Therefore, as a result of the conducted study, it was found that the number of endophytic microorganisms of apple fruits (Malus domestica) of the studied varieties changes in the range of $10^{2}-10^{7} \mathrm{CFU} / \mathrm{g}$, depending on the variety and stage of fruit development. The internal tissues of the fruits are populated by microorganisms from different systematic groups. Apparently, the plant forms and controls its internal microbiome. Hanseniaspora uvarum yeast and rod-shaped bacteria Lactobacillus and Pantoea dominate. The microorganisms with growth-stimulating, fungicidal and bactericidal activity, promising for agricultural biotechnology use, have been isolated.

\section{References}

1. C de Blackburn, Food Spoilage Microorganisms (Saint Petersburg: Professiya2011)

2. I. N.Guseva, An apple tree in your garden (Moscow : Moscow University Publ., 1991).

3. T.G.Dobrovolskaya, K.A.Khusnutdinova, N.A.Manucharova, A.V.Golovchenko, Micr $b, 86$ (2), 247-254 (2017)

4. A.M. Glushakova, Ecology of epiphytic yeast (Moscow, 2006)

5. L.P.Partida-Martinez, M. Heil Front Plant Sci.2, 100 (2011)

6. S.Narula, R.C.Anand, S.S.Dudeja, V.Kumar, Int J, 36(4), 344-350(2013)

7. A.Pitzschke,Front Microbiol, 7, 2(2016)

8. B.AmbikaManirajan, S Ratering, V Rusch, EnvironMicrobiol, 18(12), 5161-74(2016)

9. I. Yu. ChernovYeast in nature (Moscow: Association of Scientific Publications of the KMK, 2013).

10. E.N.Vasilyeva, G.A.Akhtyamova, V.A. Zhukov, I.A. Tikhonovich, Ec gen, 17(1), 1932 (2019)

11. N. GMachavariani., L. P. Terekhova, Antib \& chem, 59(5-6), 26-33(2014)

12. G. Santoyo, G. Moreno-Hagelsieb, C. Orozco - Mosqueda Mdel, B.R. Glick. MicrobiolRes, 183, 92-99 (2016)

13. S.C ompant, C. Clément, A. Sessitsch, Soil Biol Biochem.42(5), 669-678 (2010)

14. I.V. Maksimov, R.R. Abizgil'dina, L.I. Pusenkova, Appl Biochem Microbiol, 47(4), 333-345 (2011)

15. A.V. Shcherbakov, A.N.Patkin, V.K. Chebotar, Achi of sc \& tech of agr 7, 35-38 (2013)

16. Ch. Mohammed., A.M. Peterson., G.S.Tkachenko, N of Sar Un 16 (4), 420-25(2016)

17. E.Yu. Blagoveshchenskaya, E.G. Popkova, Bul of Mosc Univ 2, 17-18 (2016)

18. F.Yu. Gelzer, Symbiosis with microorganisms as the basis of plant life (Moscow: Moscow Agricultural Academy Publ,1990) 
19. A.A. Vankova, S.V. Avilova, V.N. Kornienko, A.A. Gryzunov, N of the Tim Agric Ac, 5, 149-57 (2019)

20. S.V. Avilova, A.A. Gryzunov, A.A. Vankova, Ref eq, 9,54-60 (2014)

21. L.V. Lysak, T.G. Dobrovolskaya, I.N. Skvortsova, Methods for evaluation of bacterial diversity of soils and identification of soil bacteria(Moscow: MAKSPress,2003)

22. D.J. Lane, 16S/23S rRNA sequencing (New York, John Wiley \& Sons, Inc., 1991)

23. T.J. Whiteetal. PCR prot: a g to meth \& appl, 18(1), 315-22 (1990)

24. https://blast.ncbi.nlm.nih.gov/ 